\title{
PLANO DE COMUNICAÇÃO E SUAS ESTRATÉGIAS PARA UMA LOJA DO SEGMENTO DE COLCHÕES
}

\author{
Dhiego da Silva Saraiva, Larissa Crepaldi Trindade \\ Universidade do Oeste Paulista - UNOESTE, Faculdade de Comunicação Social, Presidente Prudente, SP. E-mail: \\ dhiegocohen@outlook.com
}

\section{RESUMO}

O presente artigo apresenta os resultados finais do Projeto Experimental de Publicidade e Propaganda da FACOPP realizado junto à agência experimental "Alvo Propaganda e Marketing" no ano de 2014. Trata-se, portanto, de uma pesquisa empírica cujo objetivo geral foi apresentar soluções comunicacionais para os problemas encontrados na empresa de colchões "Sonocenter". O projeto teve início com a criação da agência experimental e sua composição, identidade visual e referências para aplicação da marca. Após essa etapa, foram realizadas as pesquisas exploratórias e de mercado para descobrir possíveis falhas comunicacionais da empresa com seu público-alvo e o posicionamento diante dos concorrentes no segmento de colchões. Finalmente, a solução encontrada para o problema de comunicação apontado pela agência experimental, baseou-se na criação de um novo posicionamento, sendo "especialista em sono" aliada às estratégias de comunicação em três fases, com o intuito de fortalecer e evidenciar a marca em seu target.

Palavras-chave: Planejamento de comunicação; público-alvo; Propaganda; loja de colchão.

\section{COMMUNICATION PLAN AND STRATEGIES FOR A MATTRESS STORE SEGMENT}

Abstract: This article brings the final results of the FACOPP Advertising and Publicity Experimental Project, realized with the "Alvo Propaganda e Marketing" experimental agency, in 2014. It is, hence, an empirical research which main goal was to present communicative solutions to the problems verified in Sonocenter mattresses company. The project started with the establishment of the experimental agency and its composition, of the visual identity and references for the application of the brand. After this stage, exploratory and market researches were done to detect possible communication mistakes of the company with its target public and its positioning regarding the competitors in the mattresses market. Finally, the solution found for the communication problem indicated by the experimental agency was the development of the new positioning: "sleep expert", which was combined with the communication strategies in three stages aiming to consolidate and highlight the brand toward its target.

Keywords: communication planning; target public; Advertisement; mattress store 


\section{INTRODUÇÃO}

Este artigo tem como proposta inicial apresentar os resultados finais de um Projeto Experimental em Publicidade e Propaganda junto ao segmento de colchões por meio de uma agência experimental, que conduziu todo o processo de estudos e pesquisa, desde o briefing, atendimento, pesquisa, marketing, planejamento de comunicação, mídia e criação.

A agência experimental teve início no ano de 2013 no sexto termo de "Comunicação Social" com Habilitação em "Publicidade e Propaganda", da Faculdade de Comunicação Social de Presidente Prudente/FACOPP/Unoeste com a proposta de solucionar os problemas de comunicação da Loja de Colchões "Sonocenter". O nome fictício da agência é "Alvo Propaganda e Marketing".

Compreendida a formação da agência experimental, foram desenvolvidas as áreas de atendimento, de supraimportância na coleta de informações através do briefing, interligando o cliente com a agência, onde foram coletados os primeiros dados do segmento de atuação da empresa, estrutura, produtos, serviços, marca, concorrentes diretos e indiretos e a comunicação que a empresa desenvolvia. Diante das informações assimiladas, foram apontados problemas na imagem e na comunicação da empresa quanto à sua exposição a produtos, marca e sua identidade visual além da ausência de um posicionamento definido. Esses problemas serão evidenciados na discussão deste artigo.

De posse das informações do briefing, a pesquisa exploratória e qualitativa teve como objetivo principal conhecer e identificar o mercado de colchões e a tendência neste segmento, descobrir a percepção de imagem pelo público-alvo, além de um meio que se possa divulgar a marca de forma efetiva.

O marketing trouxe a análise de mercado e do consumidor que designaram informações para composição da análise de SWOT ressaltando as oportunidades e ameaças, forças e fraquezas da loja de segmento de colchões "Sonocenter". Através das pesquisas e análises, foi constatada a ausência de um posicionamento que diferenciasse a marca e criasse características que pudessem conectá-la com seu consumidor. A palavra "especialista em sono", definida pelo marketing, foi a que permeou a construção do posicionamento com o objetivo de agregar valor à marca, de modo que o consumidor correlacionasse a loja, seus produtos e serviços oferecidos à qualidade de vida ao obter uma ótima noite de sono. Para isso, foram traçados objetivos estratégicos que desencadearam as estratégias de marketing.

O passo seguinte ocorreu através da elaboração do planejamento de comunicação, a qual competiu prever e organizar as ações que se enquadraram no perfil da Loja de segmento de 
colchões "Sonocenter", suprindo suas necessidades, objetivando concluir uma comunicação plausível. Por meio da investigação, foram observadas falhas na comunicação com o consumidor final, principalmente no que concerne a identificação e associação da propaganda relacionada à marca "Sonocenter" por esse público. Com base nessas premissas, evidenciadas em dados do briefing e planejamento de marketing, foram elaborados os objetivos e estratégias comunicacionais.

Os objetivos de comunicação se pautaram na construção e divulgação da marca "Sonocenter" e a criação de conceito baseado no posicionamento de "especialista em sono". Com relação às estratégias de comunicação, de acordo com a pesquisa exploratória, foram apontadas as épocas relacionadas às férias escolares (julho e dezembro) como um dos momentos em que mais se vendem colchões e também um dos momentos em que são mais acirradas as vendas neste segmento. A partir do exposto, a estruturação da campanha foi organizada em três fases: a primeira, focada no lançamento da campanha institucional, focou o conceito de especialista em sono, a inserção da mascote e divulgação do site institucional e o facebook da marca. A segunda, na sustentação da marca, seguindo a estratégia de evidenciar e trazer maior credibilidade, efetivando o posicionamento outrora mencionado com o intuito de familiarizar a mascote com o público-alvo. Por último, a manutenção da marca focando nas ações de propaganda institucional, marketing digital e merchandising.

Desse modo, nossa pesquisa apontou algumas estratégias de forma que a agência compreendeu que, por meio da campanha institucional, uma atenção especial seria dada ao conceito de marca e o posicionamento de especialidade em sono sugerido no marketing para a construção da referida, expondo maior visibilidade da marca em seu segmento.

\section{METODOLOGIA}

Esta pesquisa objetivou coletar e analisar informações a respeito de um segmento de loja de colchões, denominada "Sonocenter" na cidade de Presidente Prudente/SP, no ano de 2014. Para direcionar as ações do trabalho, foram realizadas pesquisas exploratória, quantitativa e qualitativa. Um total de 424 questionários foram aplicados. As questões foram voltadas para o conhecimento da loja de segmento de colchões acima citada bem como da importância dos funcionários no trabalho realizado junto à empresa. O objetivo foi identificar o perfil dos clientes da loja, suas preferências e considerações sobre ela.

A pesquisa quantitativa permitiu que se realizasse uma análise da situação dos funcionários dentro da empresa, levando em consideração as relações estabelecidas entre funcionários e 
empresa, funcionários e seus superiores, dentre outros. Na pesquisa de campo, foram realizadas entrevistas para verificar com o público-alvo qual o grau de conhecimento da loja no ramo de colchões, seu comportamento de compra e conhecimento sobre a referida empresa do segmento de colchões. Também foi utilizada uma consulta por telefone com os maiores vendedores de colchões da região para um conhecimento mais contundente sobre o ramo na cidade, de forma que conseguíssemos mais elementos que enriquecesse nossa pesquisa.

Para compreender, selecionar e avaliar os dados coletados, a pesquisa foi composta em quatro momentos. Inicialmente, realizamos uma pesquisa exploratória de dados secundários em diversos sites na internet. Também optamos por realizar uma consulta por telefone com os maiores vendedores de colchões da região. Em um segundo momento, na pesquisa descritivaquantitativa, os funcionários da loja foram entrevistados. Com os clientes internos selecionados, foram realizadas entrevistas por telefone. Por fim, realizamos uma pesquisa com o público-alvo através de entrevista com questionário aberto semiestruturado encadeada na cidade de Presidente Prudente/SP, e também por meio da internet, utilizando a ferramenta do Google docs.

\section{DISCUSSÃO}

Para esta discussão estaremos pautados nos resultados finais da pesquisa. A partir das entrevistas realizadas junto aos clientes internos da loja de segmentos de colchões "Sonocenter", foi constatado que, a maioria deles tem opiniões diferentes e diversas sobre a loja e seus produtos, ressaltando o meio de divulgação, a localização geográfica e também a qualidade dos produtos. Com relação à pesquisa com clientes externos da loja de segmento de colchões, a pesquisa mostra a satisfação e opinião dos clientes externos sobre o mundo dos colchões.

Quando questionado sobre o grau de importância na hora de escolher um colchão, os entrevistados levam em consideração, em primeiro lugar, a marca. Em segundo lugar, o preço. Já a loja e a indicação são o que menos levam em consideração na hora de escolher um colchão. Acerca disso, pode-se depreender a importância da marca na hora da compra. O quesito loja já não é tão importante no momento de adquirir o produto, abrindo caminhos para que se possa traçar novas estratégias, criando valor para que a loja seja reconhecida como local especializado com venda de colchões de marcas de procedência. Diante do exposto, decidimos trabalhar com a estratégia de comunicação institucional focada no posicionamento "especialista em sono" sugerido pelo marketing. O plano de comunicação buscou, em conjunto com todas as áreas da comunicação (atendimento; pesquisa; planejamento de marketing, comunicação e mídia), adaptar 
o referido de forma eficiente, visando organizar e prever as ações que se enquadrem no perfil do cliente de maneira que supra suas necessidades. Lupetti $(2009$, p.87) destaca:

A campanha institucional deve ser entendida como aquela que divulga a empresa como um todo. Caracteriza-se por conceituar a empresa, fixar sua imagem, informar seu segmento de atuação, objetivando o estabelecimento e reconhecimento de sua marca.

A ideia foi fixar o nome da loja de segmento de colchões "Sonocenter" e, portanto, ser referência no momento do consumidor pensar em adquirir um colchão, pois terá certeza de que, estará aliando a compra de um novo produto com a garantia de que o mesmo será benéfico à sua saúde, oferecendo mais conforto e qualidade na hora do descanso. Além do assinalado acima, consideramos importante tecer considerações a respeito da estratégia de campanha. Com relação ao público-alvo, como estratégia de campanha, foi utilizada a integração das ferramentas de comunicação. Portanto, houve a necessidade de utilizar ferramentas tradicionais, mescladas com as complementares e inovadoras, como a propaganda institucional, a assessoria de imprensa e o product placement. Dentre as citadas, vamos descrever a propaganda institucional como a mais relevante para o desenvolvimento da pesquisa.

A propaganda institucional, segundo Lupetti (2009, p. 13):

Para que as pessoas percebam o posicionamento de determinada organização, é preciso que haja divulgação, e a propaganda institucional auxiliará a construção da identidade e da imagem corporativa, bem como tentará conquistar a confiança, a credibilidade e a simpatia de seus stakeholders.

Podemos observar pela citação anterior que as estratégias de imagem procuram construir a identidade da marca atribuindo peculiaridades humanas ao produto. Além disso, esse mesmo processo pode ser utilizado para criar o "status" e a disposição da marca junto ao consumidor. Para o entendimento desse processo contamos com o apoio das ferramentas como website, página no facebook, mascote, assessoria de imprensa e product placement, mencionados a seguir.

Para a ferramenta de Website, optamos pela construção do valor da marca aliada à interação com os consumidores, pois é um meio institucional para transmitir informações acerca da marca e o posicionamento que é "especialidade em sono". Com relação à página no facebook, consideramos importante pensar a estratégia do humor informativo das dicas do sono através da mascote da marca. $O$ engajamento através dessa ferramenta de comunicação permitiu a interação com a marca e um público extremamente interessado em obter informações a respeito dela. 
A mascote, outro elemento de destaque, utilizada na ferramenta digital (site e facebook) também foi pensada como elemento de interação com o público-alvo. De forma humorística, a opção por fazer uso da mascote objetivou trazer dicas importantes que produzisse expectativas além do esperado. A ideia principal foi a disseminação na rede como um viral, que pôde ser compartilhada no facebook e whatsapp, tornando-se memes (termo utilizado para descrever um conceito que se espalha via internet) entre as pessoas. De acordo com Crescitelli e Shimp (2013, p. 341):

As novas mídias trazem os seguintes importantes benefícios para as empresas... a) interação com, e participação do consumidor final, por ser uma mídia de "mão dupla", b) identificação de segmentos mais específicos, c) comunicação mais eficiente e com profundidade, d) ferramentas digitais permitem larga cobertura do público-alvo, e) maior transparência e credibilidade na comunicação, f) otimização dos gastos em comunicação, uma vez que as mídias virtuais são mais baratas e é possível focar o público-alvo desejado, g) realização de testes de diferentes formas de comunicação, h) acompanhamento imediato do desempenho da campanha permitindo maior flexibilidade.

Desse modo, reiteramos a importância das mídias digitais como ferramentas que possibilitam a interação com o público-alvo, fortalecendo a marca neste segmento e possibilitando uma mensuração constante, sendo possível realizar adaptações ao longo de sua utilização.

Além das ferramentas anteriormente citadas, consideramos importante tecer considerações a respeito da "Assessoria de Imprensa". A referida objetivou contribuir para a formação da imagem da marca de forma coordenada, coerente e lógica aos meios de comunicação da região, como jornal impresso, blogs e também sites especializados em informações a respeito da saúde do sono.

Por fim, o product placement objetivou aliar e abranger toda a estratégia de comunicação, visto que é uma ferramenta que garante boa audiência e exposição da marca.

\section{RESULTADOS}

Os resultados obtidos nesta pesquisa apontam para a satisfação dos envolvidos com relação à empresa consultada. A pesquisa evidenciou que os principais fatores motivadores são: integração da equipe, imagem da empresa, estabilidade no emprego, instalação moderna e eficiente da loja.

Após a realização da pesquisa com os clientes internos, foi possível concluir que os referidos estão satisfeitos nos quesitos: atendimento; serviço de entrega; preço e produtos da loja 
de segmento de colchões "Sonocenter". No entanto, apontam uma deficiência no ponto-de-venda quanto à disposição dos produtos e a fachada da loja, o que poderia facilitar a visibilidade em sua localidade.

Os dados evidenciaram que, com o público externo, foi possível analisar que a loja de colchões "Sonocenter" é pouco conhecida na cidade. Dentre outros aspectos, ressaltamos que a marca do colchão vem sempre em primeiro lugar no momento da escolha do produto, ficando a loja em última instância.

Em tese, nossa pesquisa revelou uma certa ausência de posicionamento de mercado, elemento esse estabelecido para atribuir diferenciação no segmento de colchões. A imagem e a comunicação da empresa também foi um fator importante a ser observado, pois a deficiência constatada por meio da pesquisa tornava a marca desconhecida do público-alvo. Identificados os problemas comunicacionais, todos os estudos realizados envolvendo análise e discussão foram incisivos nas estratégias de posicionamento e desenvolvimento da comunicação no sentido de fixar a marca e torná-la evidente em seu público-alvo e segmento de atuação.

\section{CONCLUSÃO}

Finalizando a discussão, podemos afirmar que a ideia central deste artigo foi apresentar alternativas para solucionar problemas comunicacionais de um determinado cliente, no caso, o cliente aqui selecionado para o estudo foi a loja de segmento de colchões "Sonocenter" na cidade de Presidente Prudente/SP. Diante do assinalado, constatamos a importância da publicidade e da propaganda nesse segmento, ressaltando o planejamento como foco principal para que o cliente atinja suas necessidades comerciais.

Este trabalho refletiu sobre a importância de se compreender a estrutura comunicacional e o processo para compor alternativas para sua efetividade, levando em consideração as competências de investigação por meio das pesquisas, as estratégias de Marketing, o planejamento de marketing, a seleção, a organização e a comunicação da informação.

\section{REFERÊNCIAS}

CRESCITELLI, Edson e SHIMP Terence. A Comunicação de marketing: Integrando propaganda, promoção e outras formas de divulgação. 8aㅡ. Ed. São Paulo. Cengage Learning, 2013.

LUPETTI, Marcélia. Gestão estratégica da comunicação mercadológica. 2a Ed. São Paulo: Cengage Learning, 2012. 